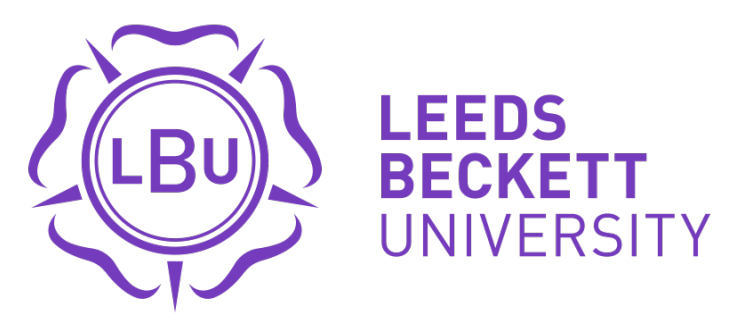

Citation:

Pickford, R (2017) Student orientation: empowering our students to be active participants and to become partners in learning. Journal of Educational Innovation Partnership and Change, 3 (2). ISSN 2055-4990 DOI: https://doi.org/10.21100/jeipc.v3i2.509

Link to Leeds Beckett Repository record:

https://eprints.leedsbeckett.ac.uk/id/eprint/4612/

Document Version:

Article (Published Version)

Creative Commons: Attribution-Noncommercial-No Derivative Works 4.0

The aim of the Leeds Beckett Repository is to provide open access to our research, as required by funder policies and permitted by publishers and copyright law.

The Leeds Beckett repository holds a wide range of publications, each of which has been checked for copyright and the relevant embargo period has been applied by the Research Services team.

We operate on a standard take-down policy. If you are the author or publisher of an output and you would like it removed from the repository, please contact us and we will investigate on a case-by-case basis.

Each thesis in the repository has been cleared where necessary by the author for third party copyright. If you would like a thesis to be removed from the repository or believe there is an issue with copyright, please contact us on openaccess@leedsbeckett.ac.uk and we will investigate on a case-by-case basis. 


\title{
Student orientation: empowering our students to be active participants and to become partners in learning
}

\author{
Ruth Pickford \\ Leeds Beckett University
}

\section{Introduction}

The nature of the orientation approaches used to support students studying in higher education is demonstrably of high importance. This is particularly true in institutions where students entering are highly diverse in their prior learning experiences and range of academic capabilities (Harvey, L., Drew, S. and Smith, M. 2006; Yorke, M. and Longden, B. 2008; Trowler, V. 2015).

This paper explores the different approaches taken across a large post-92 university to support new students to become active participants in their own learning in the early stages of their undergraduate course. A mixed-methods investigation and analysis, focusing primarily on qualitative data, was undertaken as part of an institutional initiative to increase Level 4 (First-Year) student progression. The aim of Grounded Theory (Glaser and Strauss, 1967 ), is to generate or discover a theory from data systematically obtained from social research. Grounded Theory was selected as the method for this project because of its usefulness in exploring contextual factors, interpreting, and constructing categories that might be of practical use to the actors. It is particularly valuable in educational research as it can build theory about a specific aspect of education where no theory currently exists. This work is then uniquely placed to generate theory as it is grounded in data collected from participants about a particular phenomenon. Using Grounded Theory, the different approaches to student orientation used across the institution were categorised and coded and themes were identified. In exploring barriers to, and enablers of, students' active participation, it was hoped a simple model could be generated that could be of practical help to course teams and institutions in developing more effective practices.

The paper uses course-level case studies and direct quotations from students and staff gathered in the course of the study to illustrate the perceived challenges of ensuring that all students on a course have opportunities to participate fully and the practical measures adopted to solve those challenges. Ethical approval for the project and for the recording and reporting of staff and student perspectives was gained.

Although the university of this case study runs a centrally-coordinated student induction programme, the large number and range of supplementary course-level approaches identified in the first weeks of Level 4 highlight the role of contextual and disciplinary factors in shaping effective practice. Subsequent analysis has been used to produce a model of the relationship between the underpinning conditions and activities that support students to develop as active participants in their institutions.

\section{Active participation}

Students' active participation - in classes, in their courses and in university life - is a highlydesirable undergraduate attribute. However, emerging evidence suggests that this may be an area of concern. For example, a study of the first-year experience in Australian 


\section{Case Studies}

universities (Baik, Naylor and Arkoudis, 2015) indicated that $30 \%$ of students never ask questions in class or make class presentations; that increasing numbers of students skip classes; that a large proportion of students reported never working with classmates outside classes and never working with other students on projects during class; that fewer than one in five students frequently study with other students.

In many UK institutions, student charters seek to provide a guide to expectations in terms of engagement and behaviour as well as to promote a culture of staff-student partnership (BIS, 2011; NUS and UUK, 2014). However, whilst there is value in sharing expectations about behaviours, a Higher Education Institution (HEI) is limited in terms of being able to have direct impact on an individual's active participation. Engagement is (or should be) studentowned and students' engagement with their course and in university life will be aligned with their personal goals and motivations. An individual student may rationally choose not to engage with her/his course in particular ways deemed essential by an institution if these do not align with her/his personal goals (Pickford, 2016). Initiatives designed to influence directly a student's active participation, and to remove from the student control of her/his participation, need to be thoughtfully considered and implemented with care. Students' participation and the extent to which they choose to transact with their university are ultimately not the HEl's direct responsibility. Well-intended practices that remove control from the student over matters of participation, (for example, allocating marks for contributions to face-to-face seminars or to online discussion groups, or punishing low attendance) may be less successful than focusing on setting and communicating expectations and giving students a clear rationale for these expectations.

Rather than seeking to enforce active participation, institutional responsibilities include providing the opportunity for all students to contribute in ways that align with their goals. At best, active participation may take the form of embedded, explicit and proactive consultations, whereby "opportunities are provided for students to express individual opinions, perspectives, experiences, ideas and concerns" (HEA and NUS, 2011), or extend to student partnerships in co-development or co-review of their courses. If we are to optimise the participation of students with diverse backgrounds, motivations and goals, it is necessary to identify the support and opportunities that need to be provided from the start of their higher education experiences. In order to investigate what this might look like, a panuniversity qualitative study of effective Level 4 practices was carried out in a large post-92 UK university. The next section describes how the study was undertaken.

\section{The study}

The Education Strategy of the university of this case study established, as a key area of work over five years, the development of students' learning pathways; the university's Centre for Learning and Teaching (CLT) was given responsibility for leading on activities relating to this. As part of the approach, a new forum was established for discussing and shaping approaches to learning and teaching. This forum was chaired by the Deputy Vice Chancellor (Academic), supported by CLT and open to all members of the university's learning and teaching community. An annual series of three fora focused in turn on discrete aspects of the Learning Pathway and good practice was shared and discussed. The aims were to support colleagues in reviewing the curriculum and delivery of their courses and to inform development of policy. In 2016, the focus of the three fora was on immersive induction of Level 4 students and on developing academic practices that would optimise student 


\section{Case Studies}

progression. This paper reviews the outcomes of the first investigation into practices that sought to empower new students to participate actively.

The university is structured around thirteen schools, each headed by a dean, and each of these thirteen schools is further structured into subject groups. There is a pan-university network of over 400 Higher Education Academy (HEA) Accredited Fellows (at all four levels) who work with CLT as a community of practice (Wenger, 1998), to share learning and teaching innovations across the institution. CLT also works closely with the Students' Union, regularly convening student focus groups to support learning and teaching projects. In this project, data was simultaneously collected and analysed, analytic categories and codes were developed from these and the categories were then integrated into a theoretical framework. The existing literature was used as data and compared with emerging categories to be integrated into the theory (Glaser 1992). The process took three months to complete and resulted in the collection of a rich data set of case studies and perspectives from students, deans, heads of subject, HEA fellows and staff across every discipline in the university.

The process undertaken for this project was as follows:

1. The university's network of over 400 HEA Fellows was asked to provide examples of practices from across the institution that empowered new students to become active participants;

2. A panel headed by three National Teaching Fellows, and supported by professional staff in CLT, used Grounded Theory to review the case studies; it also identified repeated elements of practice;

3. A discussion paper, based on these elements of practice, was drafted and shared and all members of the university's academic, learning and teaching community were asked to comment via an online discussion board;

4. The university's forty-nine Heads of Subject, along with student representatives and Directors of Academic Services, were subsequently invited to a pan-university halfday forum on 'Student orientation: empowering new students to be active participants';

5. Pre-forum, in-forum, and post-forum collected data were further coded (Glaser and Strauss, 1967) and a model was developed;

6. Follow-on interviews and one-to-one meetings were held with deans, academic and support staff and student representatives and the model was refined;

7. Groups were established to take forward specific change initiatives resulting from the study.

\section{Overview of findings}

Although the range of approaches was large, as data was collected and reviewed it became clear that the courses that were most successful in empowering their students to participate actively in the early stages of a course had two underpinning characteristics in common: a responsive learning environment and a well-organised, tightly-structured course. This finding aligns with the literature in the field (Biggs, 1996; Gibbs, 2010; Thomas, 2012). Discussions with students revealed that these two conditions had direct impact on students' abilities to orientate, particularly in the early stages of a course. There appears to be a strong 


\section{Case Studies}

relationship between a student's appreciation of institutional expectations, requirements, conditions and opportunities and her/his ability to participate actively.

The grounded theory analysis of case studies began with the grouping of practices into two broad categories that related directly to these notions of organised curriculum and responsive learning environment:

- $\quad$ practices that support students' practical orientation: understanding who, where and when (requiring a responsive learning environment);

- practices that support students' course orientation: understanding what, how and why (requiring an organised curriculum).

General practical orientation to higher education and the HEI and more specific orientation to the demands and culture of a course were strong features of the analysed activities.

Although all the case studies fell broadly into one or both of these two categories, some activities straddled them whilst others, perhaps unsurprisingly, combined supporting students to become active participants with, for example, development of students' independent learning skills or developing feelings of membership to a learning community (areas that were beyond the scope of this project). The next section briefly discusses the findings relating to developing students' practical orientation.

\section{Practical orientation}

"It's impossible to get anywhere fast in the first week of term, 'round every corner there's a new student asking where the finance office is or trying to understand their timetable... I remember that feeling of helplessness so well." Module leader.

Ideally, practical orientation requires that students are able to navigate around their learning environments (physical and virtual), that they know when and where to go and whom to contact for classes, development, resources, support and information. It became clear from the study that a responsive learning environment with strong, clear, proactive and accessible support is desirable for assisting students' practical orientation.

Within the category of practical orientation, almost all the case studies submitted for analysis could be further coded as:

- designing pre-emptive practical orientation activities and resources;

- prioritising rapid response systems when problems arose;

- targeting the practical orientation needs of particular student groups.

\section{Pre-emptive practical orientation activities}

Pre-designed, pre-emptive, practical orientation activities were the most commonly coded of all orientation practices identified in the study and most of these types of activity took place in the first week of the course. Induction weeks are features in most courses and there has traditionally been a tendency to consider induction as an event.

Most course teams in the study had designed very early interventions by which students' day-to-day queries and practical requirements were answered and met respectively. The Sports Coaching course, for example, designed an induction week including familiarisation 


\section{Case Studies}

with course and academic regulations, university sport facilities and team opportunities, university buildings and the Coaching staff team, and making effective use of the personal tutor system to provide a first point of contact for all students. Early focused orientation events can have the advantage of identifying and addressing student misconceptions promptly as well as ensuring that, from day one, students are aware of whom to contact.

"It was good that she [the course administrator] came to the first lecture. After that it was no big deal to ask her things." First-year student.

Many effective practices, the study found, involved course teams' providing some guidance to students' pre-arrival. The International Tourism course team, a winner of university awards including the Course Team of the Year Award, used the simple approach of sending a well-crafted and personal welcome email to students' personal email addresses. Other teams, such as Entertainment Management, invited students to join a closed Facebook group, to "begin with some knowledge of what to expect". It was clear that, whilst most courses had not invested heavily in developing pre-entry course-specific virtual tours or other sophisticated systems, many had invested time in ensuring that their students arrived at the university having had some opportunity to 'get up to speed with the lie of the land' and, in particular, having been provided with the names of contacts to whom they could go with queries.

Whilst most course teams believed they had a responsibility to ensure, as a minimum, that new students were practically orientated to their learning environments, some course teams took a broader, more holistic approach to supporting students' practical orientation. For example, the Sociology course team, recognising that most of their new students moved around a very small geographical area between halls, the university and the bars and shops in the city centre, required students in their first weeks to carry out a demographic study, taking bus trips to the suburbs, as part of a 'long, thin' induction spread out over the whole of the first semester.

"It was a really good start to the course. We were put in groups and got to decide our own topic and choose our own bus routes. It was really interesting to see how things changed along the bus route....and some of us had never really been on a bus before." First-year Sociology student.

\section{Rapid response systems}

The case study institution is one of a small number of UK universities that have explicitly developed a Service Model culture. Retaining whole-institution UK Customer Service Excellence accreditation is an institutional key performance indicator and it is therefore possibly unsurprising that, after pre-emptive practical orientation activities, the next most cited practice was the provision of rapid responses to student queries. The development of online and face-to-face systems, to provide quick advice and signposting through reception desks, helpzones, counselling and 24/7 library services, was identified by courses across the institution as a plank of practical orientation.

"We have an open door policy...we keep it informal. It's important they know they can talk to us rather than letting things build up... chances are if one student's unclear it's worth going over with the whole class." Senior lecturer. 


\section{Case Studies}

"I'm very clear with my staff. We need to be focused on supporting Level 4 students. We are moving to frontloading more resource to the first semester." Dean.

Some courses in the study that were strong on student progression proactively sought student feedback and many of them integrated professional services staff into the day-to-day operation of a course, prioritising responses to individual questions and incidents as they arose. Structures supporting student feedback and negotiation that gave individual students a voice in shaping fit-for-purpose provision served to develop students' sense of control over their environment and encouraged them, through supported, continuing consultation, to provide feedback about their conditions and resources.

"It's important to get the course reps in place quickly. A good course rep can change the whole tone." Student liaison officer.

\section{Targeting particular students and student groups}

During 2016, the institution carried out enhancement-focused projects investigating the learning experiences of black and minority ethnic (BME) students and students with disabilities across the university and, as a result, the drive to support particular student groups had a high profile in the institution at the time of the study. It was generally recognised that there might be particular orientation challenges relating to students from certain backgrounds. However, although some emerging initiatives did focus on tailored practical orientation, there were far fewer examples of these found in the study than had been expected. From the forum discussion, it became clear that for some staff this was a problematic area:

"We colonise the personal experience of students - we shouldn't. We should be open to personalisation of experiences... we have an increasingly diverse population of students. We must not be rigid in our expectations. We need to be very careful about promoting a vision of particular cultural and gendered behaviour." Forum participant.

"We culturally shoe-horn all students into our system." A different forum participant.

Monitoring systems that collect and collate information about student interactions - library loans, virtual learning environment (VLE) logins, attendance at timetabled sessions, etc. can indicate the type and level of a student's participation. Whilst there was agreement that we should be clear and transparent about what data we would collect and how it would be used, it is the case that student participation data can usefully inform the triggering of timely, targeted interventions to check on a student's engagement and wellbeing. The institution is currently developing data analytic systems, but, given the absence of sophisticated monitoring systems, one member of staff reported that it was too time-consuming and resource-intensive to track students:

"You know which students are going to struggle but there's a limit to what you can do. You just try to give them all the information and be really clear about things and hope they make it through the first few weeks. The important thing is to get them to attend. Once that goes, you know you're going to lose them." Personal tutor. 


\section{Case Studies}

Several course teams did identify tailored practical orientation initiatives they undertook to support specific student groups. The International Foundation Studies course team learned that issues arising from students' arriving late (owing to visa difficulties) could be mitigated by a programme that included an extended six-week series of guest lectures from support services. Other teams described specific practical orientation interventions designed to support evening and part-time students who were often in the university at times when some of the central services were not available to provide face-to-face information.

Practical orientation is the first of the two requirements identified in the study as a prerequisite for students to become active participants. Through subsequent coding, it was possible to identify more detailed elements in effective practical orientation approaches as discussed above. The next section briefly discusses findings relating to the second prerequisite for active participation: students' course orientation.

\section{Course orientation}

Whereas practical orientation requires students to acquire knowledge about whom to contact, where to go and when, students need also to understand what they must do on their course, how they are expected to go about this and why. Course orientation requires the sharing of standards relating to processes, transactions and behaviours. From the study, it was clear that a prerequisite for course orientation is a well-organised course. An organised curriculum needs to be coherent and well-structured, provide clear course information (including guidance about resources and technologies for learning) and have transparent, aligned, relevant assessment processes and activities (Biggs, 1996; Gibbs, 2010; Fredericks, Blumenfeld and Paris, 2004).

Most of the case studies submitted for analysis categorised as course orientation could be further coded as:

- supporting course orientation through clear operational information;

- structuring course orientation through scaffolded, staged support;

- promoting course orientation through demonstration of value and relevance.

\section{Clear operational information}

For students to be able to settle in quickly to their academic routines, operational details such as timetables, groups and processes for reporting absence need to be clearly communicated.

"There was so much information on [the VLE] and in the handbook and I wasn't sure what was important... there was a whole section on external examiners ....it would have been good if you were told what stuff you really needed to know." Second-year student.

A number of case studies referred to the design of the VLE course space to provide individual students with information specific to the student's course, including groups they were enrolled on, course announcements and contact details for course administrators and course reps. From the study, a priority for many students was that any changes to the curriculum or essential information such as module selection or room changes need to be communicated in good time. 


\section{Case Studies}

"We had this one module that was all over the place. It was in a different room every week and nobody seemed to know what was happening." [The same] Second-year student.

This appears to be particularly important to some students. It was highlighted in enhancement-focused projects that many BME students particularly valued: knowing how groups are allocated; explanations of expectations of group work behaviour; clear communication about who would take responsibility for contact between them and their personal tutor.

The importance of a strong course identity was discussed at the forum and it was felt that, in some instances, the sharing of modules between courses was hindering course orientation. Very large courses offered similar challenges:

"Modularisation is not useful - students often don't know which module they're on." Forum participant.

"There's no sense of a course as there are problems with groups getting together as they are always timetabled." Forum participant.

\section{Structured staged support}

There is considerable support in the literature for a process-focused rather than eventfocused course induction (Lowe and Cooke, 2003; Ramsden, 2008). Liz Thomas' remarks about induction activities sum up current thinking about the shape and scope of induction which she says should: "actively engage students rather than being a passive process of providing information, and extend over a longer time period than a few days." (Thomas, 2012, p.25).

This view of induction as a longitudinal process usefully challenges the traditional norm of viewing 'induction week' as a one-off event, whereby students come out of the week inducted, ready to fully engage with all aspects of their course. A number of case studies focused on scaffolding new students through the first stages of the course - the first seminar, the first assessment, the first journey between campuses. There was also a focus on ensuring consistency across a course, particularly in the earliest stages and introducing students to standards:

"Students need to know what's what. We show them exemplar assignment answers in the second week. How can we expect students to produce good work if they don't know what good is?" Module leader.

It is clear also that assessment design is critical to scaffolding participation:

"We use a variety of small assessments at the beginning of the course." Forum participant.

"We must use assessment to bring students to something meaningful." A different Forum participant.

Little things make a big difference. On the Songwriting and Production course, new students were provided with an introductory package, including assignment schedules, detailed work- 


\section{Case Studies}

planners promoting clear deadlines and staff photoboards "to encourage students to feel more comfortable approaching staff" and to support them through the first semester.

"It's the aggregation of marginal gains - supporting your new students with the dayto-day and helping them develop the habits they need." A Head of Subject commenting on the Songwriting course approach.

Additionally, course teams in the study who had implemented proactive approaches to ensuring that students were participating reported a positive impact on student retention:

"The first time they miss one of my classes I phone them.... You nip it in the bud. I think some of them are quite shocked, but it's important they know l've noticed and care."Senior lecturer.

\section{Value and relevance}

Any structured programme, however carefully it is designed, runs the risk of not meeting the individual requirements of students and of disengagement of any students who are unable or disinclined to participate actively. There are particular challenges with mixed-ability groups:

"It is incredibly challenging to plan sessions given the range of experience and capabilities of our students and we are hampered by the lack of information we have about our students." Forum contributor.

Some case studies were designed to demonstrate to individual students the value of learning activities and assignment tasks and were intended to be useful, informative and relevant to student interests and future goals, as well as relating course requirements to real world contexts and to students' previous experiences. This approach can be useful in orientating students to course requirements (Fredericks et al, 2004; Thomas, 2012). Course design, delivery, discussion, and an open-door policy form the basis of the International Tourism course team's strategy to encourage active participation:

"Design a relevant, engaging and fun course - and then teach it with huge amounts of enthusiasm. Ask the students what they think all of the time," and, "communicate with the students as equals." Course leader.

It can be a successful strategy to indicate to new students how activities feed into the course objectives. A senior lecturer teaching first-year Psychology students reported making explicit use of learning outcomes to signpost students, providing:

"...a level of transparency as to what we are actually looking for in terms of their learning at a session-by-session level."

Moving from a lens of 'student induction into the HEl', to a service model, whereby the course team and the broader institution are inducted into their new students' contexts, goals, and needs so that they can support each student through a relevant curriculum, represents a paradigm shift for many academics and others who support student learning. However, there is a growing sense that a person-focused, rather than an event- or process-focused induction, can best foster the development of a culture which provides relevant opportunities for each student and supports embedding of staff-student partnerships. 


\section{Case Studies}

\section{Discussion}

Student progression is a key performance indicator for many HEls in the UK and in many nations and the Bourn Report (2007) clearly links student orientation to retention. Whilst any student's progression on her/his course will be determined by a number of factors, one key desirable undergraduate attribute that positively correlates with progression is clearly the extent of a student's active participation (Trowler, 2010).

By adopting a Grounded Theory approach to the investigation of activities supporting students' active participation, the study described in this paper enabled the university to access rich information. The findings of this study suggest that having an orientation strategy clearly communicated to students, alongside expectations and available support, is the first step in engaging students. Students who are both practically orientated and orientated to the demands of their course are empowered to participate fully and actively in their course. At the highest level, course orientation, supported via an organised, relevant curriculum and practical orientation and realised through a responsive learning environment, should provide embedded opportunities for new students to become active participants in their learning.

\section{An active participation model}

Based on the findings from this investigation an active participation model was generated (Figure 1), representing the conditions that support active participation and underpin student progression. Using Grounded Theory to analyse practices across one institution, approaches within each of the categories of practical and course orientation were further coded:

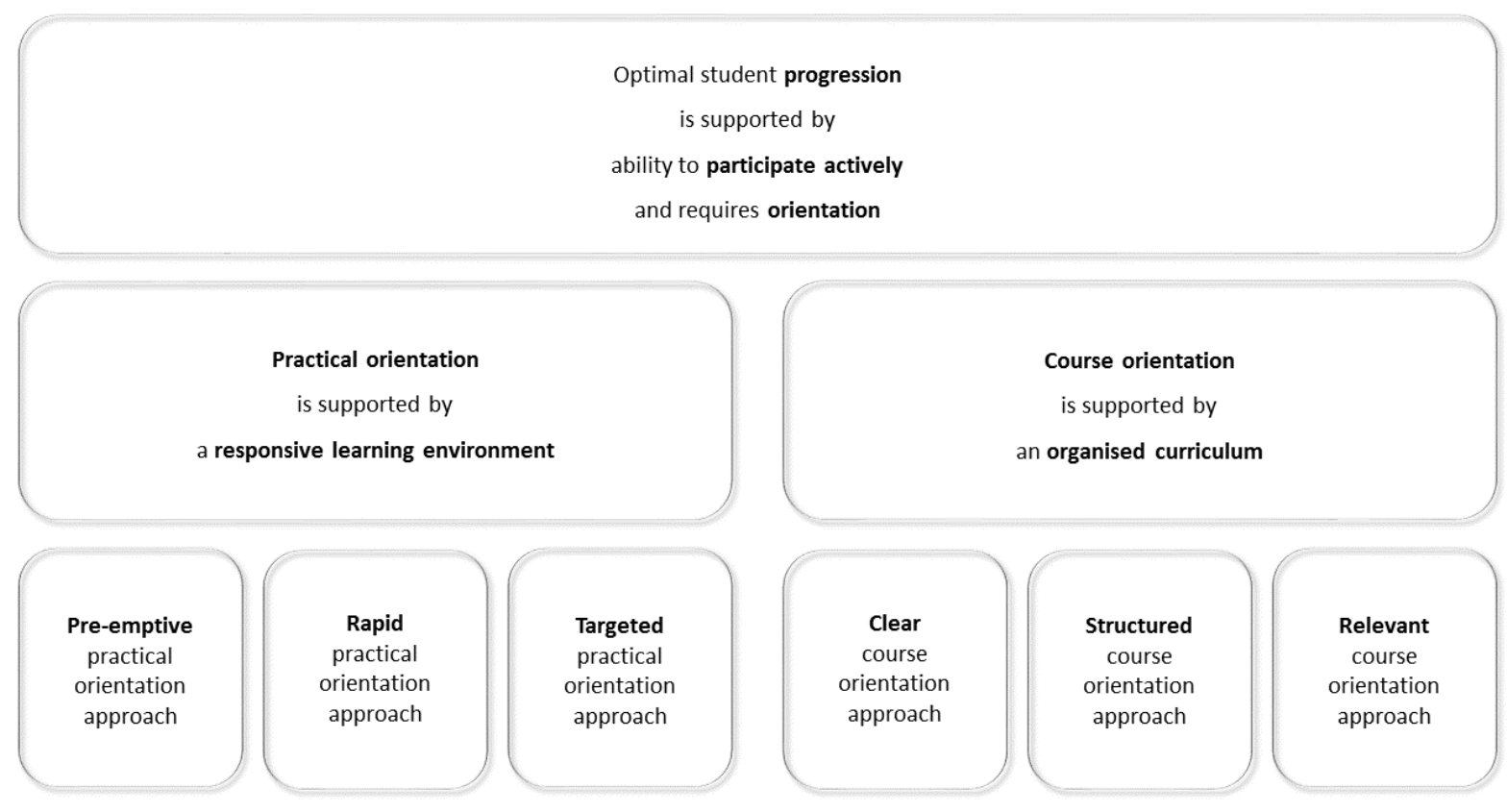

Figure 1. A grounded theory model of active participation 


\section{Case Studies}

\section{Transferability of the approach}

There are some recognised limitations to this study. Firstly, the study was focused on practices within one university and it is possible that the organisational culture influenced the approaches taken. It was notable, however, that, although there were course-level differences, the major features described were visible across a range of courses from different disciplines. Secondly, the methodology relied on HEA Fellows and Senior Fellows within the university to identify effective practices and then on a forum of Subject Heads and students to share their perceptions of the effectiveness of these approaches. These might be a particular subset of university teachers and leaders with a specifically reflective and committed approach to teaching and learning and this might have affected their perspectives. Furthermore, had students been asked independently to suggest successful strategies, this might have identified different activities and categories.

The research for, and the outputs from, this project were governed by practicalities of time. This investigation of student participation was carried out as part of a study of the Level 4 learning and teaching processes in one university which itself formed part of a five-year development of that university's entire learning pathway. The relatively short amount of time, the focus on practices in only one institution and the process of theoretical narrowing during data collection possibly limited the emergence, in this study, of other factors underpinning successful orientation practices. It is difficult to judge whether theoretical saturation has been reached and it is not suggested that this is a fully-developed, comprehensive model. It does, however, represent what is happening and under what conditions at this time in one university.

Nevertheless, the research suggests clear transferability to other universities, both of the method used to collect data and the implementation of the outcomes derived from this study.

\section{Conclusions and recommendations}

Active student participation is a prerequisite for development of staff-student partnerships. The active participation model presented in this paper has been designed to synthesise the findings from this investigation and to provide a vehicle for course teams to use when considering how best to foster their students' active participation. Student participation is a complex area and cannot be considered in isolation from other aspects of students' learning experiences, such as personal and social integration, developing their sense of belonging, disciplinary and academic preparation and the development of independent learning skills. If HEls are to optimise student progression, a holistic approach to the design of the First-Year curriculum, teaching approaches and learning environment must be adopted.

There were some interesting and unforeseen outcomes of this project. Firstly, the study revealed nuanced features of orientation approaches that accommodated particular student cohorts and student and staff contexts. There were strong views expressed by staff and students that a level of autonomy was required if course teams were to support effectively their students' orientation and that centrally-coordinated induction activities could, if not integrated with course-level processes, act as a distraction or even confuse new students. A reconsideration of the role and the value of institutional orientation programmes in satisfying diverse student needs may therefore be useful. 


\section{Case Studies}

Secondly, an area of contention sharply highlighted by this project, which requires further investigation, is the relationship between student attendance and active participation and the approach to student attendance that should be taken. There were clear and strong differences of opinion across both staff and student groups on the matter, with some believing that attendance was so critical to active participation that student attendance enforcement policies should be implemented, whilst others were clear that students should be able to choose to engage with their courses in ways that fit with their individual requirements.

"It should not matter if they attend ... accept [that] students engage in the way they want to engage." Student representative, Forum.

"We need to rethink the University... we are ritualistic and just being in class isn't what it's about." Principal lecturer, Forum.

Whilst a senior academic leader suggested:

"Students are investing in their futures and there is a responsibility that goes with it. We have a moral responsibility to ensure students maximise their learning."

Finally, an outcome of this project for the university concerned has been a rethinking of the purpose of orientation at the host institution. The project set out specifically to investigate the range of approaches in use to support students to become active participants, but is leading to an extensive reframing of the concept of orientation. Traditionally, orientation had been regarded as a process of orientating the student. There is a developing recognition that a primary purpose of orientation in relation to transition into university study is the opportunity it presents for the institution to learn about and develop a programme of support to meet each student's transitional requirements. One key outcome of the forum was a commitment to investigate how far the institution could go, within data protection regulations, in sharing information about students that could help staff provide more tailored support. It is suggested that an institution's orientation to its students (rather than students' orientation to the institution) may well be the most important factor in empowering students to be active participants.

\section{Reference list}

Baik, C., Naylor, R. and Arkoudis, S. (2015) The first year experience in Australian universities: findings from two decades, 1994-2014. Melbourne: Melbourne Centre for the Study of Higher Education, The University of Melbourne.

Biggs, J. (1996) 'Enhancing teaching through constructive alignment.' Higher Education, 32(3), 347-364.

BIS (2011) Student charter group: final report. Department for Business Innovation and Skills.

Bourn, J. (2007) Staying the Course: the Retention of Students in HE. National audit Office. Available at: https://www.nao.org.uk/wp-content/uploads/2007/07/0607616.pdf (Accessed: 6 June 2017). 


\section{Case Studies}

Fredricks, J.A., Blumenfeld, P.C. and Paris, A.H. (2004) 'School Engagement: Potential of the Concept, State of the Evidence.' Review of Educational Research. 74(1), 59-109.

Gibbs, G. (2010) Dimensions of quality, York: The Higher Education Academy.

Glaser, B.G. (1992) Basics of grounded theory analysis: Emergence vs. forcing. Mill Valley, CA: Sociology Press.

Glaser, B.G. and Strauss, A.L. (1967) The discovery of grounded theory: Strategies for qualitative research. New York: Aldine de Gruyter.

Harvey, L., Drew, S. and Smith, M. (2006) The first-year experience: A literature review for the Higher Education Academy. York: HEA. Available at:

https://www.heacademy.ac.uk/system/files/first_year_experience_exec_summary.pdf (Accessed: 6 June 2017).

HEA and NUS (2011) Student Engagement Toolkit. Higher Education Academy and National Union of Students. Available at: (Accessed: 6 June 2017).

Lowe, H. and Cooke, A. (2003) 'Mind the Gap: Are students prepared for higher education?' Journal of Further and Higher Education, 27(1), 53-76.

NUS and UUK (2014) Building a Framework for Partnership with Students. Available at: http://www.nusconnect.org.uk/resources/building-a-framework-for-partnership-with-students (Accessed: 6 June 2017).

Pickford, R. (2016) 'Student Engagement: Body, Mind and Heart - A Proposal for an Embedded Multi-Dimensional Student Engagement Framework.' Journal of Perspectives in Applied Academic Practice, 4(2).

Ramsden, P. (2008) The Future of Higher Education Teaching and the Student Experience. York: The Higher Education Academy.

Thomas, L. (2012) Building student engagement and belonging in higher education at a time of change: a summary of findings and recommendations from the What Works? Student Retention \& Success programme. York: The Higher Education Academy.

Trowler, V. (2010) Student Engagement Literature Review. York: The Higher Education Academy. Available

at: https://www.heacademy.ac.uk/studentengagement/Research and evidence base for st udent engagement (Accessed: 6 June 2017).

Trowler, V. (2015) 'Negotiating Contestations and Chaotic Conceptions: Engaging NonTraditional Students in Higher Education.' Higher Education Quarterly, 69(3). Available at: DOI: 10.1111/hequ.12071. (Accessed: 6 June 2017).

Wenger, E. (1998) Communities of Practice: Learning, Meaning, and Identity. Cambridge: Cambridge University Press. ISBN 978-0-521-66363-2. 


\section{Case Studies}

Yorke, M. and Longden, B. (2008) The first-year experience of higher education in the UK: Final Report. York: The Higher Education Academy. Available at:

https://www.heacademy.ac.uk/system/files/fyefinalreport 0.pdf (Accessed: 6 June 2017). 